\title{
Prevalence of Unruptured Intracranial Aneurysms: A Single Center Experience Using 3T Brain MR Angiography
}

\author{
Jae Ho Kim, $\mathrm{MD}^{1}$, Kyung-Yul Lee, MD, $\mathrm{PhD}^{2}$, Sang Woo Ha, $\mathrm{MD}^{3}$, Sang Hyun Suh, MD, PhD \\ ${ }^{1}$ Department of Neurosurgery, Gangnam Severance Hospital, Yonsei University College of Medicine, Seoul, Korea \\ ${ }^{2}$ Department of Neurology, Gangnam Severance Hospital, Yonsei University College of Medicine, Seoul, Korea \\ ${ }^{3}$ Department of Neurosurgery, Chosun University Hospital, Chosun University College of Medicine, Gwangju, Korea \\ ${ }^{4}$ Department of Radiology, Gangnam Severance Hospital, Yonsei University College of Medicine, Seoul, Korea
}

Purpose: The purpose of this study was to evaluate the prevalence and risk factors of unruptured intracranial aneurysms (UIAs), which can help establish guidelines of treatment for asymptomatic Korean adults using 3T magnetic resonance angiography (MRA).

Materials and Methods: Our Institutional Review Board approved this retrospective study, and informed consent was waived. All patients consisted of healthy individuals who underwent brain MRA using 3T magnetic resonance imaging between January 2011 and December 2012 as part of a routine health examination. Patient data and follow-up results were obtained from medical records.

Results: A total of 2,118 individuals (mean age $=53.9 \pm 9.6$ years, male:female $=1,188: 930$ ) who had undergone brain MRA were enrolled in the study. UIAs were found in 80 patients with 105 UIAs (3.77\%). Female predominance ( $55 \%$ in UIA vs. $43.47 \%$ in non-UIA, $P=0.0416)$ and hypertension were more common in the UIA group ( $43.75 \%$ vs. $28.8 \%, \mathrm{P}=0.004$, respectively). The mean size of the aneurysms was $3.10 \pm 1.62 \mathrm{~mm}$, and they were all saccular in shape and asymptomatic. The UIAs were most common in the internal carotid artery (59.1\%), internal carotid-posterior communicating artery (15.2\%), middle cerebral artery (9.5\%), anterior communicating artery (8.6\%), anterior cerebral artery (4.8\%), and vertebral artery (2.9\%). Twenty-eight of 80 patients (35\%) had multiple aneurysms. The incidence of UIAs increased significantly with age $(\mathrm{P}=0.014)$.

Conclusion: In single center experience, we demonstrated the characteristics and prevalence of UIAs in asymptomatic adults, which may help establish guidelines or therapeutic standards for UIAs.

Key Words: Intracranial aneurysm; Magnetic resonance angiography; Cross-sectional study; Prevalence

\section{Correspondence to: Sang Hyun Suh, MD, PhD Department of Radiology, Gangnam Severance Hospital, Yonsei University College of Medicine, 211 Eonju-ro, Gangnam-gu, Seoul 06273, Korea Tel: $+82-2-2019-3510$ \\ Fax: +82-2-3462-5472 \\ E-mail: suhsh11@yuhs.ac}

Received: January 12, 2021 Revised: February 17, 2021 Accepted: March 8, 2021
Copyright $\odot 2021$ Korean Society of Interventional Neuroradiology This is an Open Access article distributed under the terms of the Creative Commons Attribution Non-Commercial License (http://creativecommons.org/licenses/by-nc/4.0) which permits unrestricted non-commercial use, distribution, and reproduction in any medium, provided the original work is properly cited. 


\section{INTRODUCTION}

Unruptured intracranial aneurysms (UIAs) are found in approximately $3.2 \%$ of the adult population without comorbidity $^{1}$ and there has been an increasing tendency to detect UIAs due to widespread use of high-resolution magnetic resonance imaging (MRI). After the international subarachnoid aneurysm trial (ISAT) trial, the relative safety and efficacy of coiling and surgical clipping were demonstrated in preventing hemorrhage from the treated aneurysm. ${ }^{2-4}$ Moreover, advances in devices and increased experience in aneurysm treatment continue to result in improvements in clinical outcomes and safety. However, the major concern when a UIA is detected is still whether to treat it or to manage it conservatively. In the real world, there is a lack of evidence on the treatment of UIAs, except for two prospective studies. ${ }^{5,6}$

Regarding the treatment strategy for UIAs, it is important to understand their natural history. Especially, the prevalence of UIAs shows a big discrepancy among several studies according to the populations studied, method of case confirmation, imaging modalities, and study design, such as prospective or retrospective. In a previous meta-analysis, the incidence of UIAs ranged from $0 \%$ to $41.8 \%$. ' In Korea, some authors suggested a UIA prevalence from $1.5 \%$ to $5 \%$ in adults where 1.5 T MRI was used. ${ }^{7,8}$

The purpose of this study was to evaluate the prevalence and associated risk factors of UIAs, which can help to establish guidelines of treatment in healthy Korean adults when $3 T$ MRI is used.

\section{MATERIALS AND METHODS}

\section{Patient selection}

Our Institutional Review Board approved this retrospective study, and informed consent was waived. All patients consisted of healthy individuals who underwent brain MR angiography (MRA) between January 2011 and December 2012 as part of a routine health in Gangnam Severance Checkup Center. They paid at their own expense for their brain imaging. Patient data including age, sex, comorbidities (hypertension, diabetes, hyperlipidemia, previous stroke history, and smoking), family history of cerebrovascular disease (intracerebral hemorrhage, subarachnoid hemorrhage, or cerebral infarction), and follow-up results were obtained from medical records. Patients were excluded if they had fusiform, traumatic, or mycotic aneurysms, which have different etiologies, or aneurysms in an extradural location.

\section{Image acquisition and interpretation}

All 3-dimensional time-of-flight MRA was performed by using 1 of 2 3.0T MRI systems at our institution (Discovery MR750; GE Medical Systems, Milwaukee, WI, USA/Achieva; Philips Medical Systems, Best, The Netherlands). MRA was performed with the following parameters for the Discovery MR750 instrument: repetition time/echo time, 23/2.5 ms; flip angle, 20 degrees; field of view, $210 \times 185 \mathrm{~mm}$; 4 slabs (176 slices); slice thickness, 1.4 mm; matrix, 416×224; and acquisition time, 5 minutes and 9 seconds. MRA was performed with the following parameters for the Achieva instrument: repetition time/echo time, 25/3.5 ms; flip angle, 20 degrees; field of view, 250×198 mm; 1 slab (170 slices); slice thickness, $1.4 \mathrm{~mm}$; matrix, 832×414; and acquisition time, 6 minutes and 52 seconds.

UIA was defined as abnormal focal outpouchings of the cerebral artery. ${ }^{6}$ All radiologic reports from both instruments were reviewed, and 2 experienced neurologists (KY Lee and SH Suh) independently reviewed the MRA images of patients with UIA and possible UIA according to those reports. In cases of discrepancy, a consensus interpretation was made. Patients with known UIAs before the MRA were also included regardless of treatment.

Aneurysm size was measured by the largest diagonal measurement. Aneurysm locations were classified as internal carotid artery (ICA), anterior cerebral artery, anterior communicating artery, middle cerebral artery (MCA), posterior communicating artery, and vertebrobasilar artery (including vertebral artery, basilar artery, posterior cerebral artery, and anterior and posterior cerebellar arteries). In addition, multiple aneurysms and the presence of daughter sacs were analyzed.

The enrolled patients were divided into 2 groups, a UIA group and a non-UIA group, which were compared according to the above criteria.

\section{Statistical analysis}

Continuous variables were described as mean \pm standard deviation, and categorical variables as frequencies in percentages. Differences between the 2 groups were evaluated using an Independent 2-sample t-test for continuous variables and the chi-square test (or Fisher's exact test) for categorical variables. The Mantel-Haenszel chi-square test was used to 
Table 1. Demographics of all patients

\begin{tabular}{|c|c|c|c|c|}
\hline Characteristics & Total $(n=2,118)$ & Aneurysm - $(n=2,038)$ & Aneurysm $+(n=80)$ & P-value \\
\hline Age (y) & $53.87 \pm 9.59$ & $53.75 \pm 9.61$ & $57.05 \pm 8.77$ & 0.0025 \\
\hline Female & $930(43.91)$ & $886(43.47)$ & $44(55.00)$ & 0.0416 \\
\hline Hypertension & $622(29.37)$ & $587(28.80)$ & $35(43.75)$ & 0.004 \\
\hline Diabetes & $241(11.38)$ & $227(11.14)$ & $14(17.50)$ & 0.0788 \\
\hline Hyperlipidemia & $189(8.92)$ & $177(8.68)$ & $12(15.00)$ & 0.052 \\
\hline Previous stroke & $20(0.94)$ & $20(0.98)$ & $0(0.00)$ & - \\
\hline Smokers & $711(33.57)$ & $689(33.81)$ & $22(27.50)$ & 0.2412 \\
\hline
\end{tabular}

Values are presented as mean \pm standard deviation or number (\%).

\section{Table 2. Characteristics of unruptured intracranial aneurysms}

\begin{tabular}{lc}
\hline Characteristic & Yes $(n=105)$ \\
\hline Location & $10(9.5)$ \\
MCA & $9(8.6)$ \\
ACOM & $62(59.1)$ \\
ICA & $16(15.2)$ \\
IC-PCOM & $0(0.0)$ \\
BA & $3(2.9)$ \\
VA & $5(4.8)$ \\
ACA & $3.10 \pm 1.62$ \\
Mean size & \\
Groups by aneurysm size (mm) & $64(60.95)$ \\
$<3$ & $35(33.33)$ \\
$3 \leq$ size<7 & $6(5.71)$ \\
$\geq 7$ & $28(35)$ \\
Multiplicity* & $2(1.90)$ \\
Daughter sac & $73(69.52)$ \\
Angiography & $4(3.81)$ \\
\hline Previous aneurysm treatment &
\end{tabular}

Values are presented as number (\%) or mean \pm standard deviation. MCA, middle cerebral artery; ACOM, anterior communicating artery; ICA, internal carotid artery; IC-PCOM, internal carotidposterior communicating artery; BA, basilar artery; VA, vertebral artery; ACA, anterior cerebral artery.

*Multiple aneurysms were seen in 28 of 80 patients.

compare trends between groups according to age. All P-values were considered statistically significant if they were 0.05 or less. Analyses were performed using SAS version 9.4 (SAS Institute Inc., Cary, NC, USA).
Table 3. Incidence of unruptured intracranial aneurysms according to age group

\begin{tabular}{lcccc}
\hline & \multicolumn{4}{c}{ Aneurysm } \\
\cline { 2 - 5 } Age group & $\begin{array}{c}\text { Total } \\
(n=2,118)\end{array}$ & $\begin{array}{c}\text { No } \\
(n=2,038)\end{array}$ & $\begin{array}{c}\text { Yes } \\
(n=80)\end{array}$ & P-value \\
\hline Age $(y)$ & 150 & $148(98.67)$ & $2(1.33)$ & 0.0144 \\
$<40$ & 503 & $488(97.02)$ & $15(2.98)$ & \\
$40 \leq$ age $<50$ & 912 & $876(96.05)$ & $36(3.95)$ & \\
$50 \leq$ age $<60$ & 433 & $414(95.61)$ & $19(4.39)$ & \\
$60 \leq$ age $<70$ & 120 & $112(93.33)$ & $8(6.67)$ & \\
$\geq 70$ & & &
\end{tabular}

Values are presented as number (\%).

\section{RESULTS}

\section{Patient characteristics}

A total of 2,118 individuals (mean age $=53.87 \pm 9.59$ years, male:female $=1,188: 930$ ) who had undergone brain MRAs for personal health check-ups were enrolled in the study. In Table 1, the mean age of the UIA group was significantly higher than that of the non-UIA group $(57.05 \pm 8.77$ years vs. $53.75 \pm 9.61$ years, $P=0.0025$, respectively). Female predominance (55\% in UIA vs. $43.47 \%$ in non-UIA, $P=0.0416)$ and hypertension were more common in the UIA group (43.75\% vs. $28.8 \%, P=0.004$, respectively).

\section{Prevalence and characteristics of UIA}

In total, 80 patients had 105 UIAs (3.77\%). The mean size of the aneurysms was $3.10 \pm 1.62 \mathrm{~mm}$, and they were all saccular in shape and asymptomatic (Table 2). The locations of UIAs were as follows: ICA (62/105, 59.1\%), internal carotid-posterior communicating artery (16/105, 15.2\%), MCA (10/105, 9.5\%), anterior communicating artery (Acom, 9/105, 8.6\%), anterior 
cerebral artery $(5 / 105,4.8 \%)$ and vertebral artery $(3 / 105,2.9 \%)$. Multiple aneurysms were seen in 28 of 80 patients (35\%); 2 UIAs in 14, 3 UIAs in 1, and 4 UIAs in 3. Although more than $60 \%$ of UIAs were less than $3 \mathrm{~mm}$ in size, 6 were more than $7 \mathrm{~mm}$ in size (5.71\%). Diagnostic angiography was performed for confirmation in 73 patients, and 4 patients were treated previously with unruptured aneurysms.

\section{Incidence of UIAs according to aging}

The incidence of UIAs increased significantly with aging ( $P=0.0144$ ), which was $1.33 \%$ in less than 40 years, $2.98 \%$ in the 40 s, $3.95 \%$ in the 50 s, $4.39 \%$ in the 60 s, and $6.67 \%$ in the 70 s (Table 3). Especially compared to the overall prevalence of UIAs in this study, the incidence of UIAs was higher in patients aged more than 50 years, and patients aged more than 70 years showed approximately double the overall incidence.

\section{DISCUSSION}

This study demonstrated that the prevalence of UIAs was $3.77 \%$ in asymptomatic adults, which was similar to a recent meta-analysis of UIAs. In autopsy cases, ${ }^{9}$ an incidence of $4.6 \%$ was suggested in UIAs, and Ujiie et al. ${ }^{10}$ showed $2.7 \%$ using conventional angiography. Jeon et al. ${ }^{7}$ described a higher incidence of 5\% in 3,049 healthy individuals using 1.5T MRI. In the era of 3T MRI, Li et al. .1 found a prevalence of $7.0 \%$ in 4,813 Chinese adults aged 35 to 75 years, and Imaizumi et al. $^{12}$ showed a prevalence of $4.32 \%$ in 4,032 Japanese healthy adults. Moreover, $60.95 \%$ (64/105) of UIAs were less than 3 $\mathrm{mm}$ in this study, which may be possible to detect by using 3T MRI. Although Vlak et al.' presented an incidence of 3.2\% (95\% confidence interval 1.9-5.2), differences among the prevalence of UIAs according to ethnic group, imaging method/device, or gender ratio should be taken into consideration.

The distribution of UIAs in this study was not much different from previous publications. The most common location of UIAs was ICA with an incidence of $74.3 \%$ in our study, which was comparable to other studies. ${ }^{1,70,13}$ In total, $8.6 \%$ of UIAs were found in the Acom, which had the highest tendency of rupture compared to others in the Unruptured Cerebral Aneurysm Study of Japan (UCAS Japan). ${ }^{6}$ The incidence of MCA aneurysms was $9.5 \%$ in this study, which was lower than in previous studies, and MCA aneurysms had a lower rupture risk than other aneurysm locations. ${ }^{6}$ UIAs in posterior circulation showed a low incidence in general, and our study revealed only $2.9 \%$ in the vertebral artery. Although some retrospective studies ${ }^{14,15}$ showed posterior circulation aneurysms have a high risk of rupture, other prospective studies ${ }^{6,16}$ did not demonstrate a high rupture risk due to the small sample size of posterior circulation aneurysms.

Our study showed an incidence of multiple aneurysms to be quite higher than in previous publications. ${ }^{7,11-13}$ Iwamoto et al. ${ }^{9}$ reported an incidence of $21.3 \%$ for multiple UIAs, and 2 prospective Japanese studies for UIAs showed an incidence of multiple aneurysms to be $26.4 \%$ in the UCAS Japan ${ }^{6}$ and $33.2 \%$ in the Small Unruptured Intracranial Aneurysm Verification (SUAVe) study, ${ }^{16}$ which showed a similar result with ours. Although this result may have some bias due to its retrospective nature, it is important to contemplate multiple UIAs as a major factor for aneurysm growth and rupture. 14,17

In this study, there were some limitations to interpret the results for UIAs due to the ethnic bias of the Korean adult population, and UIAs were determined using MRA, which has some disadvantages for the detection of small UIAs. Although our study has the strength of a large number of asymptomatic participants and the application of 3T MRA, further longitudinal studies will need to evaluate the life of UIAs.

\section{CONCLUSION}

In this single center experience, we demonstrated the characteristics and prevalence of UIAs in asymptomatic adults, which may help establish guidelines or therapeutic standards for UIAs.

\section{Fund}

This study was supported by the Korean Society of Interventional Neuroradiology (KSIN) research grant 2020.

\section{Ethics Statement}

Our Institutional Review Board approved this retrospective study, and informed consent was waived.

\section{Conflicts of Interest}

The authors have no conflicts to disclose. 


\section{Author Contributions}

Concept and design: SHS. Analysis and interpretation: SHS and KYL. Data collection: SHS and KYL. Writing the article: SHS and JHK. Critical revision of the article: SWH, SHS and KYL. Final approval of the article: SHS. Statistical analysis: JHK and SWH. Obtained funding: KSIN research grant 2020. Overall responsibility: SHS.

\section{ORCID}

Jae Ho Kim: https://orcid.org/0000-0002-6292-5223

Kyung-Yul Lee: https://orcid.org/0000-0001-5585-7739

Sang Woo Ha: https://orcid.org/0000-0002-0409-2737

Sang Hyun Suh: https://orcid.org/0000-0002-7098-4901

\section{REFERENCES}

1. Vlak MH, Algra A, Brandenburg R, Rinkel GJ. Prevalence of unruptured intracranial aneurysms, with emphasis on sex, age, comorbidity, country, and time period: a systematic review and meta-analysis. Lancet Neurol 2011;10:626-636

2. Thompson BG, Brown RD Jr, Amin-Hanjani S, Broderick JP, Cockroft KM, Connolly ES Jr, et al.; American Heart Association Stroke Council, Council on Cardiovascular and Stroke Nursing, and Council on Epidemiology and Prevention; American Heart Association; American Stroke Association. Guidelines for the management of patients with unruptured intracranial aneurysms: a guideline for healthcare professionals from the American Heart Association/American Stroke Association. Stroke 2015;46:23682400

3. Molyneux AJ, Kerr RS, Yu LM, Clarke M, Sneade M, Yarnold JA, et al.; International Subarachnoid Aneurysm Trial (ISAT) Collaborative Group. International subarachnoid aneurysm trial (ISAT) of neurosurgical clipping versus endovascular coiling in 2143 patients with ruptured intracranial aneurysms: a randomised comparison of effects on survival, dependency, seizures, rebleeding, subgroups, and aneurysm occlusion. Lancet 2005;366:809-817

4. Molyneux A, Kerr R, Stratton I, Sandercock P, Clarke M, Shrimpton J, et al.; International Subarachnoid Aneurysm Trial (ISAT) Collaborative Group. International subarachnoid aneurysm trial (ISAT) of neurosurgical clipping versus endovascular coiling in 2143 patients with ruptured intracranial aneurysms: a randomised trial. Lancet 2002;360:1267-1274

5. Wiebers DO, Whisnant JP, Huston J 3rd, Meissner I, Brown RD Jr, Piepgras DG, et al.; International Study of Unruptured Intracranial Aneurysms Investigators. Unruptured intracranial aneurysms: natural history, clinical outcome, and risks of surgical and endovascular treatment. Lancet 2003;362:103-110

6. UCAS Japan Investigators, Morita A, Kirino T, Hashi K, Aoki N, Fukuhara $S$, et al. The natural course of unruptured cerebral aneurysms in a Japanese cohort. N Engl J Med 2012;366:2474-2482

7. Jeon TY, Jeon P, Kim KH. Prevalence of unruptured intracranial aneurysm on MR angiography. Korean J Radio/ 2011;12:547-553

8. Park S, Lee DH, Ryu CW, Pyun HW, Choi CG, Kim SJ, et al. Incidental saccular aneurysms on head MR angiography: 5 years' experience at a single large-volume center. J Stroke 2014;16:189-194

9. Iwamoto H, Kiyohara Y, Fujishima M, Kato I, Nakayama K, Sueishi K, et al. Prevalence of intracranial saccular aneurysms in a Japanese community based on a consecutive autopsy series during a 30-year observation period. The Hisayama study. Stroke 1999;30:1390-1395

10. Ujiie H, Sato K, Onda H, Oikawa A, Kagawa M, Takakura K, et al. Clinical analysis of incidentally discovered unruptured aneurysms. Stroke 1993;24:1850-1856

11. Li MH, Chen SW, Li YD, Chen YC, Cheng YS, Hu DJ, et al. Prevalence of unruptured cerebral aneurysms in Chinese adults aged 35 to 75 years: a cross-sectional study. Ann Intern Med 2013;159:514-521

12. Imaizumi Y, Mizutani T, Shimizu K, Sato Y, Taguchi J. Detection rates and sites of unruptured intracranial aneurysms according to sex and age: an analysis of MR angiography-based brain examinations of 4070 healthy Japanese adults. J Neurosurg 2018;130:573-578

13. Harada K, Fukuyama K, Shirouzu T, Ichinose M, Fujimura H, Kakumoto K, et al. Prevalence of unruptured intracranial aneurysms in healthy asymptomatic Japanese adults: differences in gender and age. Acta Neurochir (Wien) 2013;155:2037-2043

14. Ishibashi T, Murayama Y, Urashima M, Saguchi T, Ebara M, Arakawa $\mathrm{H}$, et al. Unruptured intracranial aneurysms: incidence of rupture and risk factors. Stroke 2009;40:313-316

15. Wermer MJ, van der Schaaf IC, Algra A, Rinkel GJ. Risk of rupture of unruptured intracranial aneurysms in relation to patient and aneurysm characteristics: an updated meta-analysis. Stroke 2007;38:1404-1410

16. Sonobe M, Yamazaki T, Yonekura M, Kikuchi H. Small unruptured intracranial aneurysm verification study: SUAVe study, Japan. Stroke 2010;41:1969-1977

17. Matsumoto K, Oshino S, Sasaki M, Tsuruzono K, Taketsuna S, Yoshimine $T$. Incidence of growth and rupture of unruptured intracranial aneurysms followed by serial MRA. Acta Neurochir (Wien) 2013;155:211-216 